\title{
Analysis of the Chinese Civic Awareness Development on the Internet ${ }^{+}$
}

\author{
Langlang Liu \\ Shaanxi University of Technology, Hanzhong 723001, China; lang23826@hotmail.com \\ + Presented at the IS4SI 2017 Summit DIGITALISATION FOR A SUSTAINABLE SOCIETY, Gothenburg, \\ Sweden, 12-16 June 2017.
}

Published: 9 June 2017

\begin{abstract}
The civic awareness covers four logical parts: consciousness of rights, consciousness of responsibility, consciousness of participation and consciousness of rule. Thanks to the public space expanded by Internet, the civic awareness has emerged rapidly. Nonetheless, there are tendencies of over-emphasis on personal rights, ignorance of rights of others, lack of consciousness of responsibility, and strong but irrational participation. Moreover, as the rule is less legally-binding and recognized, people are hardly aware of that.
\end{abstract}

Keywords: network; civic awareness; network order

\section{Introduction}

The civic awareness in China grew slowly in previously underdeveloped area until the leap of Internet in the late 1990s. Since then there has been rapidly-rising civic awareness in China. At present, Internet is the best platform for Chinese civil society. And the civic awareness contains four parts at least. First, the consciousness of rights is the foundation. Second, the consciousness of responsibility should be included. Third, citizens with the consciousness of rights and responsibility are supposed to participate into public affairs with actual actions and express their opinions, so as to contribute to the social development. Last but not least, citizens should have the consciousness of rule, and observe social rules.

\section{Current Realities of the Civic Awareness on the Internet in China}

The Internet is a promoter of the rise of consciousness of rights, which is the core of civic awareness. In Chinese traditional culture, the value of "ego" was neglected while that of community was emphasized. Furthermore, the lack of consciousness of rights among Chinese people is a consequence of incomplete channels. The consciousness of rights of Chinese people has grown fast through the Internet as the most effective and cost-saving channel.

Netizens lack the consciousness of responsibility, which refers to their positive duty implementation according to their social status as masters of the country. However, it is common that netizens emphasize their personal rights too much with ignorance of responsibilities and others' rights. Therefore, to maintain the order of Internet through moral self-discipline of netizens, it is a must to enhance their consciousness of responsibility.

The consciousness of participation has been developing in practice. This consciousness is essentially a sense of state master that citizens actively participate into the operation of public power as members of the community. In China, there are following significant features in people's participation. First, they pay much attention to public events. Second, they are keen on political issues. And third, they are concerned with social equality and justice. Generally speaking, the consciousness of participation of Chinese people develops rapidly, and the Internet is the best channel for Chinese people to participate into the operation of state power. 
Unreasonable rules cause lack of consciousness of rule among netizens. The consciousness of rule indicates awareness of rule-observation and rule-maintenance on the basis of recognition. Yet because of ineffective implementation, the current laws, rules and conventions on the Internet fail to regulate people well. As we have found, the rule-making, without participation of netizens (which is a procedure misplacement), has the reasonableness questioned. The theoretical core of such doubts is the recognition of the ruled as the foundation of reasonableness of the government.

The effect regulation is established on the two following points. First, it is actively accepted by netizens, not passively by any external power or opinion. As Rawls puts it, "present him with considerations that enable him to accept the constraints on his conduct." Second, the participation of netizens is indispensable to rule-making.

\section{Conclusions}

Thanks to the Internet, the consciousness of rights, responsibility, participation and rule has developed rapidly in China. Certainly there are some problems and controversies in the course, but the Internet is the best platform for the development of civic awareness in China. It takes more time.

In addition, we do not regard these problems and controversies as barrios. Instead, they help to enhance the civic awareness of Chinese people as well as their qualities as citizens, which can promote China to a well-ordered modern country with a perfect system in smooth evolution.

\section{References}

1. Rawls, J. A Theory of Justice [M]; Harvard University Press: Cambridge, MA, USA, 1999; p. 338. 